\title{
Giant Cecal Lipoma Causing Intussusception
}

\author{
Arif Aslaner, Tuğrul Çakır, Kemal Eyvaz, Murat Kazım Kazan \\ Department of General Surgery, University of Health Sciences, Antalya Training and \\ Research Hospital, Antalya, TURKEY
}

\begin{abstract}
Colonic lipomas are usually seen as small dimensions in the cecum and ascending colon of elderly women. Many of colon lipomas are asymptomatic and diagnosed incidentally during endoscopy or surgery. As diameter increases it can cause symptoms such as bleeding, obstruction or intussusceptions. 53 years old female patient was admitted to the emergency department with ongoing intermittent abdominal pain more significantly over the past year with nausea and vomiting. On routine physical examinations more pronounced abdominal tenderness and rebound was observed in the right lower quadrant. At blood count leucocytosis was measured as 15,300. Other biochemical parameters were normal. Air-fluid levels were detected on abdominal graphy, bowel dilatation and a mass of $7 \times 5 \times 4 \mathrm{~cm}$ in diameters in cecum, compatible with lipoma reported by ultrasound and computed tomography, The patientunderwent laparotomy the mass which cause the lumen almost completely obstructed was palpated in the cecum with proximal bowel dilatation. A right hemicolectomy and ileotransversostomy was performed. Histopathologic examination of the resected specimen was reported as lipoma consisting of grossly compatible with yellow microscopic fatty cells. On the fifth postoperative day the patient was discharged uneventfully without any complaints and complications. We report a case of giant cecal lipoma causing intussusseption who admitted to our clinic and discharged successfully.
\end{abstract}

Keywords; lipoma, intussusception, cecum

\section{Introduction}

Colonic lipomas are rarely detected at colonoscopy, surgery or autopsy incidentally (1). Lipomas of cecum and ascending colon are usually asymptomatic and no treatment was needed. If diameter exceed $2 \mathrm{~cm}$, symptoms, such as abdominal pain, bleeding, obstruction, intussusception, and even weight loss ca be seen (2-6) We report a 53 year old woman, who presented a large pedunculated cecal lipoma with ulcerated mucosa $(7 \mathrm{~cm}$ in greatest dimension). The patient underwent right hemicolectomy and side to side anastomosis was performed. The lesion was diagnosed as submucosal lipoma at cecum histopathologically.

\section{Case Report}

A 53 year old female patient was admitted to our emergency department with intermittent right lower quadrant abdominal pain of one year duration with nausea and vomiting. She had no any relevant medical or surgical history, On the physical examination the abdomen was mildly distended, with right lower quadrant tenderness with rebound in the right iliac fossa. No abdominal mass was palpated. Routine laboratory tests showed leucocytosis (15.300), hemoglobin $10.3 \mathrm{~g} / \mathrm{dL}$; all other blood tests were within normal limits. Air fluid levels on right lower abdominal quadrant were showed at plain abdominal X-ray findings, plain chest X-ray and electrocardiography findings were nonspecific. Abdominal computed tomography revealed a $7 \times 5 \mathrm{~cm}$ diameter in sized intraluminal cecal mass with intestinal dilatation. Exact details of the procedure were explained and a patient informed consent was obtained. The patient was taken to operating room. At laparatomy, colo-colonic intussusception in the right colon with dilatation of proximal intestine was seen and right hemicolectomy and side-to-side anastomosis were performed. At the postoperative 5th day she was discharged from the hospital without any complication. Macroscopic appearence of the resected right hemicolectomy specimen shows a pedunculated polypoid tumor at cecum of $7 \times 5 \times 4 \mathrm{~cm}$ diameters in size causing intussusception of the cecum into the ascending colon (Figure-1). Histopathological examination of the resected specimen proved the diagnosis of submucosal lipoma at cecum. 


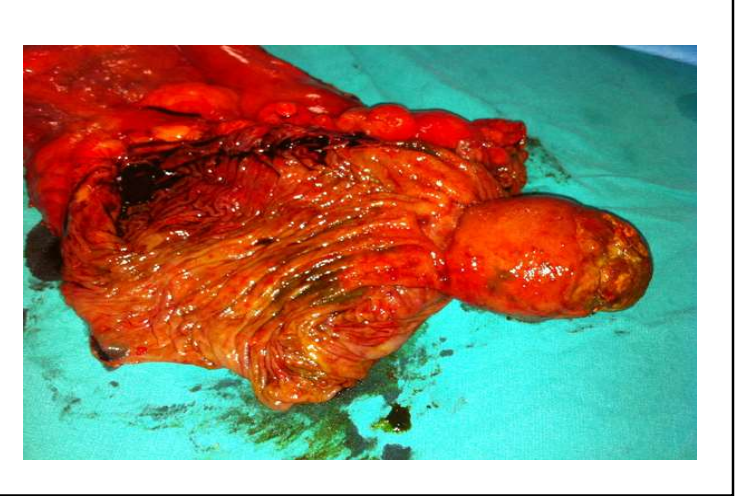

Fig-1: Macroscopic appearence of a pedunculated polypoid tumor with ulcerated overlying mucosa at cecum of right hemicolectomy resection specimen

\section{Discussion}

Lipomas are rare benign tumors of the gastrointestinal tract, mostly seen in the right colon. Incidence of colonic lipomas ranges from 0.2 to $4.4 \%$ (7). Lipoma of colon arises in the submucosa and extends in to the muscularis propria or subserosa. Usually, the lipomas are solitary, but can be multiple (8). Colonic lipomas usually do not cause symptoms $(\% 75)$ and are seen at colonoscopy, surgery or autopsy incidentally. Symptoms such as abdominal pain, diarrhea, rectal bleeding, constipation, nausea and vomiting, weight loss, bowel obstruction were seen (2-6)

Colonic lipomas are small polypoid masses mainly seen in the cecum and ascending colon, $(3,9)$

The etiology of gastro intestinal system lipomas is not well understood yet (10). In many cases they are truely neoplastic lipomas and arise from the submucosa with a well circumscribed margin and protrude into the lumen. They have a polypoid appearance, and rarely extend to muscularis propria, even subserosa. The lipoma may be a result of chronic inflammation, especially in the cecum. The chronic infammatory process may result in abnormal intestinal motility and this may cause the mucosa to pull away from the deeper submucosa, resulting in the creation of a tissue space with subsequent adipose tissue deposition. The deposited adipose tissues have no well-defined margins with adjacent tissues, and the overlying and adjacent colonic mucosa always presents with inflammatory changes, as in our current case. In this situation, it is better to call a pseudolipoma to distinguish from the true neoplastic lipoma. However, the differentiation of neoplastic lipoma and pseudolipoma is not well recognized and still controversial.

For diagnosis of colonic lipomas; colonoscopy may allow direct visualization of the submucosal colonic lipomas. Colonoscopic biopsies can confirm the tumor nature. Barium enema studies are not diagnostic for especially colonic lipomas. Prefered noninvasive diagnostic method for colonic lipomas is Computerized Tomography scan. Ultrasonographic features of this benign tumor are not characteristic. Magnetic Resonance imaging was recently used modality.(11)

Various treatment options of lipomas of colon are present. Generally, small lipomas of colon with pedicle can be safely removed endoscopically. Surgical resection is recommended for symptomatic large lipomas or to reduce the risk of underlying malignancy. (12) A segmental resection, hemicolectomy or subtotal colectomy may be necessary in cases when diagnosis is questionable or when a complication occurs. If the preoperative diagnosis of colonic lipoma can be made correctly, the extent of surgery may be appropriately limited. $(13,14)$

In conclusion, we report a case of giant cecal lipoma with intussusseption which was treated successfully.

\section{References}

1 Jiang L, Jiang LS, Li FY, Ye H, Li N, Cheng NS, Zhou Y. Giant submucosal lipoma located in the descending colon: a case report and review of the literature. World J Gastroenterol 2007; 13: 56645667

2 Katsinelos P, Chatzimavroudis G, Zavos C, Pilpilidis I, Lazaraki G, Papaziogas B, Paroutoglou G, Kountouras J, Paikos D. Cecal lipoma with pseudomalignant features: a case report and review of the literature. World J Gastroenterol 2007; 13: 2510-2513

3 Meghoo CA, Cook PR, McDonough CA, Bowser LK, Waddell BE. Large colonic lipoma with mucosal ulceration mimicking carcinoma. Gastrointest Endosc 2003; 58: 468-470

4 El-Khalil T, Mourad FH, Uthman S. Sigmoid lipoma mimicking carcinoma: case report with review of diagnosis and management. Gastrointest Endosc 2000; 51: 495-596

5 Vasiliadis K, Katsamakas M, Nikolaidou A, Christoforidis E, Tsalis K, Tsalikidis A. Submucosal lipoma of the ascending colon as a source of massive lower gastro-intestinal bleeding: a case report. Acta Chir Belg 2008; 108: 356-359

6 de Ruijter SH, van Marle AG, Doornewaard H, Melse JC. [Submucosal lipoma of the colon: abdominal cramps with rectal bleeding and weight loss] Ned Tijdschr Geneeskd 2006; 150: 1990-1993

7 Weinberg T, Feldman M Sr. Lipomas of the gastrointestinal tract. Am J Clin Pathol 1955; 25: 272-281

8 Napolitano L, D'Aulerio A. [A case of colonic multiple lipoma] G Chir 2003; 24: 295-297

12 Purohit V, Joshi R, Kalla AR, Purohit RC. Colo-colic intussusception due to intestinal 
lipomatosis. Indian J Gastroenterol 2003; 22: 151152

9 Cossavella D, Clerico G, Rosato L, Galetto PV, Paino O, Trompetto M, Luc AR, Pozzo M. [Lipoma of the colon as an unusual cause of recurring partial intestinal occlusion. Clinical case and review of the literature] Minerva Chir 1998; 53: 277-280

10 Worthen WF 2nd, Worthen N, State D, Hirose FM. Lipoma of the cecum clinically simulating carcinoma. Dis Colon Rectum 1979; 22: 270-273

11 Paskauskas S, Latkauskas T, Valeikaite G, Paseliunas A, Svagzdys S, Saladzinskas Z, Tamelis A, Pavalkis D. Colonic intussusseption caused by colonic lipoma: a case report. Medicina 2010; 46: 477-481.

$12 \mathrm{CrP}$, Colquhuon PH. Intussusseption in adults. Can J Surg 2007; 50:13-14.

13 Ghidirim G, Mishin I, Gutsu E, Gagauz I, Danch A, Russu S. Giant submucosal lipoma of the cecum: report of a case and review of literature. Rom J Gastroenterol 2005; 14: 393-396

14 Tascilar O, Cakmak GK, Gün BD, Uçan BH, Balbaloglu H, Cesur A, Emre AU, Comert M, Erdem LO, Aydemir S. Clinical evaluation of submucosal colonic lipomas: decision making. World J Gastroenterol 2006; 12: 5075-5077 